Article

\title{
Research of the Behavior of Clay Materials with Double Porosity
}

\author{
Hynek Lahuta ${ }^{1, *(D)}$ and Luis Andrade Pais ${ }^{2}$ \\ 1 Faculty of Civil Engineering, VŠB-Technical University of Ostrava, 70800 Ostrava, Czech Republic \\ 2 Faculty of Engineering, University of Beira Interior, 6200-001 Covilhã, Portugal; ljap@ubi.pt \\ * Correspondence: Hynek.lahuta@vsb.cz
}

check for

updates

Citation: Lahuta, H.; Pais, L.A. Research of the Behavior of Clay Materials with Double Porosity. Sustainability 2021, 13, 3219. https://doi.org/10.3390/su13063219

Academic Editor: Alessandro Cavallo

Received: 31 December 2020

Accepted: 1 February 2021

Published: 15 March 2021

Publisher's Note: MDPI stays neutral with regard to jurisdictional claims in published maps and institutional affiliations.

Copyright: (c) 2021 by the authors. Licensee MDPI, Basel, Switzerland. This article is an open access article distributed under the terms and conditions of the Creative Commons Attribution (CC BY) license (https:// creativecommons.org/licenses/by/ $4.0 /)$.

\begin{abstract}
This contribution presents results from a series of compression and undrained triaxial tests to study the mechanical behavior of dump clay from the north of Bohemia. The use of these materials as a foundation for construction can't be achieved without the adoption of some precautions. This comes from embankment, formed by digging the ground (altered claystone), up to the level of coal mining which is in a sub horizontal stratigraphic layer. A potential static liquefaction behavior was observed in undrained tests for high confinement stress. A structural collapse was noticed with the results obtained in the triaxial test. This collapse is characterized by an unexpected large decrease in deviator and mean effective stress. The soils formed have strength properties that are potentially dangerous. These concepts can improve the use of these kinds of soils in geotechnical engineering work. It continues and expands the results obtained in previous research, especially the future problematic use of these materials as the foundation soil for line or building structures.
\end{abstract}

Keywords: triaxial test; laboratory measurement; dumps material

\section{Introduction}

The basic literature important for the topic of this article is represented by the authors [1-4]. They have investigated the fundamental mechanics of sands and clays in triaxial and oedometer apparatus and found similar behavior with the mechanical shape of curves with simple frameworks.

The purpose of this paper is to review some of the laboratory test data performed in dump clay from North Bohemia with the aim of understanding better the mechanics of these materials. This material comes from mines landfills. Many slopes were formed without rigorous density control and put into question the safety of these slopes because there is danger of potential liquefaction. Static liquefaction and instability have similar effective stress paths and are associated with large increases in pore pressure promoting mechanisms of strain softening [5].

A series of undrained triaxial compression tests $(\mathrm{CU})$ at isotropic consolidation stresses from 50 to $350 \mathrm{kPa}$. The series of oedometer tests are used to estimate the compressibility parameters and the stress-strain and strength rupture behavior. The study is realised in a molded soil of a compacted dumping of mines. The CU and compressibility tests were carried out on two series of samples: remolded and intact/stabilized. The soils have a low permeability $\left(k \approx 10^{-9} \mathrm{~m} / \mathrm{s}\right)$ and when loaded the water pore pressure increase instantly a number near the total stress, canceling the effective stress. This situation is defined static liquefaction. Some potential for static liquefaction is displayed after investigating the preconsolidation stress and the strength parameters. The liquefaction potential index proposed by Charles et al. (2004) [6] is used to provide a preliminary design parameter for static liquefaction and instability of inclined slopes. 


\section{Trial Research and Soil Category}

\subsection{Particle Size Distribution}

The current essay takes a clay soil as start point. The dump material is composed of fine soil and waste of coal. The clay is the product of meteoric alteration of claystone a fine grained siliciclastic sedimentary rock from the tertiary age. The dump soils were produced by the alteration of claystone (and was excavated until stratigraphic level of the coal and deposited into countertops.

The particle size distribution, liquid limits and particle density were used to the physical characterization of soils which are necessaire for the soil mechanical behavior interpretation. Soil identification tests was carried out following a British Standards protocols [7].

Particle size distribution results are represented in Figure 1.

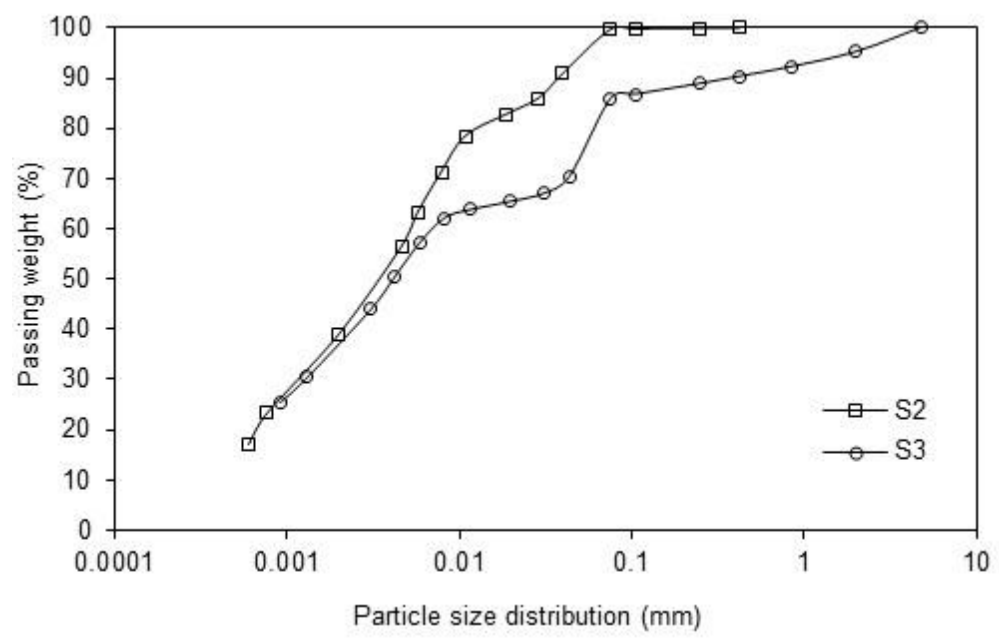

Figure 1. Particle size distribution of S2 and S3 samples.

In dumping soil, the particle size distribution shows that the addition coal quite changes the original dimension of the particles distribution and we have a not uniform distribution (see $\mathrm{S} 3$ grain size distribution).

The plasticity index (22\%) is lower in clean and coal soil. According to the limit of consistency (S3: $\mathrm{LC}=0.89$ and S2: $\mathrm{LC}=1.18$ ), the soils go from hard to stiffness behavior. The coals inside soils, is the responsible for the decreasing of water moisture at liquid and plastic limit as the coal substitutes the clays capacity of absorbent water and are most likely to increase the particles lubrication. The coal and clean soil belong to the CL group (low plasticity clay-unified soil classification). The S2 and S3 are silty and sandy clay respectively according to the ASTM classification [8], which can be described as inorganic clay of low to medium plasticity with normal or low clayey activity (clayey activity is between 0.56 to 0.58), confirming the existence of kaolinite mineral which is probably the consequence of chemical weathering of feldspar minerals. This is the least expansive clay and it explains the low plasticity and clayey activity in this soil.

The concentration of coal is dependent of sampling level. Two samples were obtained: (i) dump soil without coal (base of the embankment) (S2); (ii) dump soil with various degrees of coal, called coal soils (inside the embankment) (S3). It was excavated until stratigraphic level of the coal and deposited into countertops. The samples were taken through boreholes at different depths, transported hermetically to the laboratory, and cut to the required dimensions (see Figure 2, photos of intact sample preparation for a triaxial testing). 


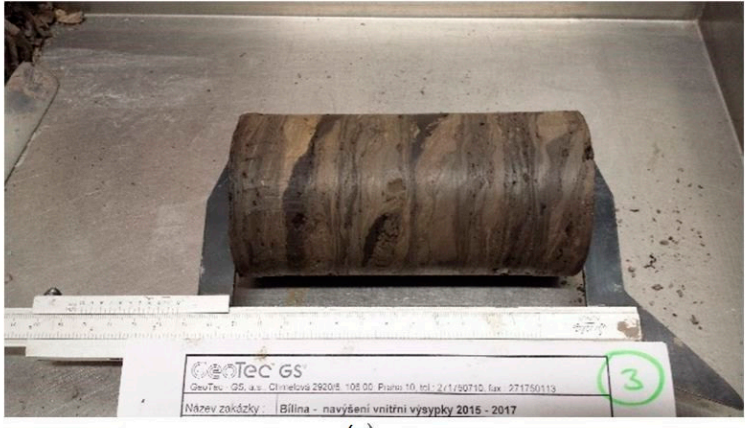

(a)

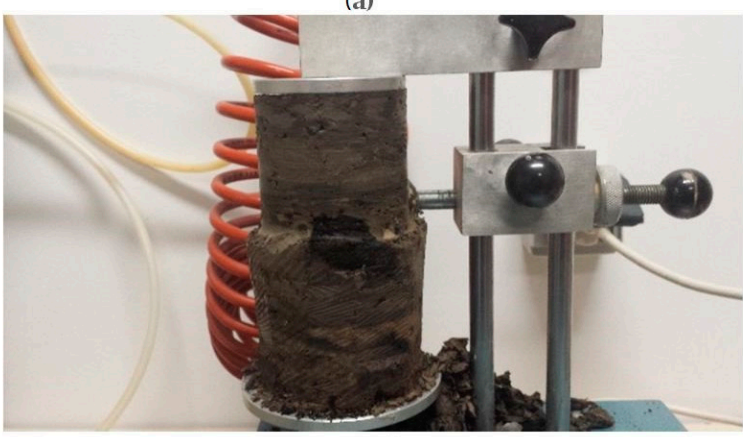

(c)

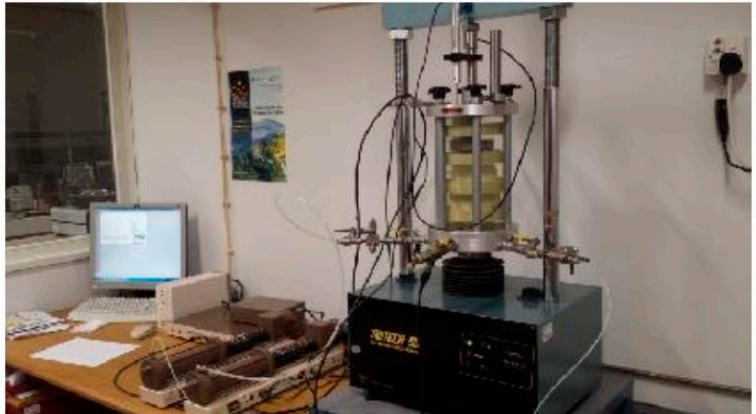

(b)

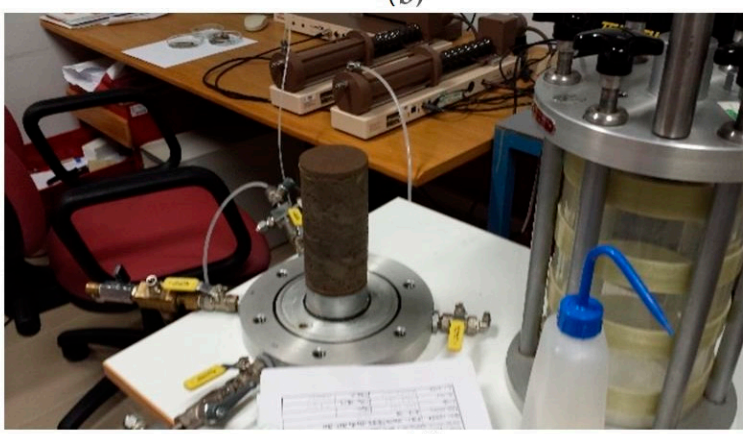

(d)

Figure 2. The tests were carried out at University of Beira Interior in Portugal. (a) Original sample from borehole; (b) sample during testing. (c) Change diameter intact sample to triaxial testing (diameter $70 \mathrm{~mm}$ ); (d) sample to be ready triaxial tested (photos prof. Pais).

\subsection{Scanning Electron Microscope (SEM)}

The clay mineralogy is an important factor controlling the physical, chemical, and mechanical properties. There are big differences on the behavior of each mineral type. The chemical (X-ray) tests show in both tests the presence of quartz $\left(\mathrm{SiO}_{2}\right)$, kaolinite $\left[\mathrm{Al}_{2} \mathrm{Si}_{2} \mathrm{O}_{5}(\mathrm{OH})_{4}\right]$ Siderite $\left(\mathrm{FeCO}_{3}\right)$, and muscovite $\left[\mathrm{KAl}_{2} \mathrm{Si}_{3} \mathrm{AlO}_{10}(\mathrm{OH})_{2}\right]$.

That on S2 and S3 samples can mainly be found silica (55-58\%), aluminum (25\%) and iron oxide (7-10\%), which are typical components of claystone. The coal soil (S3) is also composed of carbon elements (signs), which can be responsible for stiffness decrease. The scanning electron microscope (SEM) micrographs of soils have been conducted to study elements and oxides components of the samples (see Table 1).

Table 1. Mass percent (\%) of chemical oxides in samples of dump clay from Bohemia.

\begin{tabular}{ccccccc}
\hline \multirow{2}{*}{ Sample } & \multicolumn{7}{c}{ Mass Percent (\%) } \\
\cline { 2 - 7 } & $\mathbf{M g O}$ & $\mathrm{Al}_{2} \mathbf{O}_{3}$ & $\mathbf{S i O}_{2}$ & $\mathbf{K}_{\mathbf{2}} \mathbf{O}$ & $\mathrm{TiO}_{2}$ & $\mathbf{F e}_{2} \mathbf{O}_{3}$ \\
\hline S2 & 1.460176 & 26.86517 & 58.13053 & 4.222983 & 1.73856 & 7.582585 \\
\hline S3 & 1.63252 & 26.81454 & 55.72307 & 3.551319 & 2.045119 & 10.23344 \\
\hline
\end{tabular}

\section{Tests and Procedures}

Using the ring of 31.5 radius and $20 \mathrm{~mm}$ height for the S2 and S3 soils, they were used for several series of oedometric tests under a $\mathrm{K}_{0}$ condition with null radial strain on saturated specimens. We conducted a test using horizontal orientation for the principal stress (S3I-H) and the other was done in an unsaturated way until it reached an increment of $191 \mathrm{kPa}$ and from now on saturated until the end of the test (S3I-V: Dry Sat), to verify the capacity of collapsibility. In this oedometer study the initial stress stage were $1.2 \mathrm{kPa}$ and the maximum vertical effective stress were $3067 \mathrm{kPa}$. The subsequent stage was the double of the previous stress stage during $24 \mathrm{~h}$. The first effective vertical stress has to contemplate the development of structural stress (bonding) yielding, which is normally low. 
The groups of specimens for oedometer tests were prepared with similar physical parameters. The samples of S2 and S3 soils were obtained from intact (I) soil of embankment and the other remolded (R). The remolded specimens were compacted in a split mold to minimize any distortion, using water contents and dry bulk density approximately equal to natural moisture [6]. Their physical properties are represented on Table 2.

Table 2. Physical parameters for oedometric tests in saturated and dry-saturated samples of dump clay from Bohemia.

\begin{tabular}{ccc}
\hline Sample & $\gamma_{\mathbf{d}}\left(\mathbf{k N} / \mathbf{m}^{\mathbf{3}}\right)$ & $\boldsymbol{v}_{\mathbf{0}}(-)$ \\
\hline S3R-V & 12.04 & 2.190 \\
\hline S3I-H & 12.80 & 2.059 \\
\hline S2I-V & 13.46 & 2.787 \\
\hline S2R-V & 11.94 & 2.015 \\
\hline S3I-V: dry to sat & 15.89 & 2.659 \\
\hline
\end{tabular}

Several series of consolidated undrained triaxial compression tests (CU) with pore water pressure and axial strain measurements, were carried out on dump clay. All remolded samples (S3R) were compacted using the same effort. Their physical properties and testing conditions are represented on the Table 3.

Table 3. Testing conditions and physical parameters for undrained tests on saturated samples of dump clay from Bohemia.

\begin{tabular}{ccccc}
\hline Reference & $\mathbf{p}_{\mathbf{0}} \mathbf{(}(\mathbf{k P a})$ & $\boldsymbol{\gamma}_{\mathbf{d}} \mathbf{( \mathbf { k N } / \mathbf { m } ^ { \mathbf { 3 } } )}$ & $\mathbf{S}_{\mathbf{r}} \mathbf{( \% )}$ & $\boldsymbol{v}_{\mathbf{0}}(\mathbf{- )}$ \\
\hline S2I (Intact) & 50 & 12.6 & 100.0 & 1.920 \\
\hline \multirow{2}{*}{ S3I (Intact) } & 50 & 13.7 & 76.2 & 1.920 \\
\hline \multirow{2}{*}{ S3R (Remolded) } & 150 & 14.6 & 100.0 & 1.810 \\
\cline { 2 - 5 } & 200 & 14.8 & 89.5 & 1.780 \\
\cline { 2 - 5 } & 300 & 13.1 & 47.9 & 2.010 \\
\hline
\end{tabular}

The triaxial set on the cell were saturated, when the reference $B$ is higher than $95 \%$ ( $\mathrm{B}=\Delta \mathrm{u} / \Delta \sigma_{3}: \Delta \mathrm{u}$, pore pressure variation and $\Delta \sigma_{3}$, cell pressure variation) and consolidated for several isotropic consolidation stress or different initial average effective stress. The saturation of each specimen was ensured by water flow followed by application of back pressure. After saturation and isotropic consolidation for different initial average effective stress, CU compression tests were carried out at an axial compression velocity of $0.003 \mathrm{~mm} / \mathrm{s}$.

\section{Results and Discussion}

It is noticeable from oedometric tests an increase of virtual preconsolidation stress $\left(\sigma_{p *}^{\prime}\right)$ for the soils influenced by artificial lateral heart stress (S3I-H: $\sigma_{p *}^{\prime}=100 \mathrm{kPa}$ ) and the developed suction for dry-saturated test (S3I-V: Dry_Sat: $\sigma_{p *}^{\prime}=96 \mathrm{kPa}$ ). The S3I-V $\left(\sigma_{p *}^{\prime}=25 \mathrm{kPa}\right)$ sample, has a preconsolidation stress less than S2I-V $\left(\sigma_{p *}^{\prime}=49 \mathrm{kPa}\right)$, for saturated tests, and explained to be at a lower depth. The virtually intact specimen (S2I-V) and the remolded specimen $(\mathrm{S} 2 \mathrm{R}-\mathrm{V})$ have the same preconsolidation stress $\left(\sigma_{p *}^{\prime}=49 \mathrm{kPa}\right)$. This is explained by destructuration processes of the original soil in the construction of the landfill. For this reason, it is preferable to call specimen virtually intact. As for the S3I-V soil, the increase of virtual preconsolidation stress doesn't has a relation with the proportion of the coal.

The stress-strain-strength performance of soils is described by a set of parameters that are defined in the failure moment. Corresponding parameters were used to the maximum 
value of shear stress $\left[t_{\text {peak }}=\left(\frac{\sigma_{1}-\sigma_{3}}{2}\right)\right]$, to axial deformation exceeding $10 \%$, to estimate the envelope corresponding to the maximum strength. The values obtained in the failure of specimens for axial deformation exceeding $20 \%$ were also considered, to estimate the envelope in its ultimate limit state $\left[t_{\text {residual }}=\left(\frac{\sigma_{1}-\sigma_{3}}{2}\right)\right]$. This criterion was displayed as fitting the limitation of axial strain allowed by the classical triaxial test. Figure 3 shows the failure envelope for the maximum shear stress $\left(t_{\text {peak }}\right)$ and the ultimate limit state or residual state $\left(t_{u l t}\right)$ in the shear stress versus mean effective stress $\left(s^{\prime}-t\right)$ space, for the stress levels used.

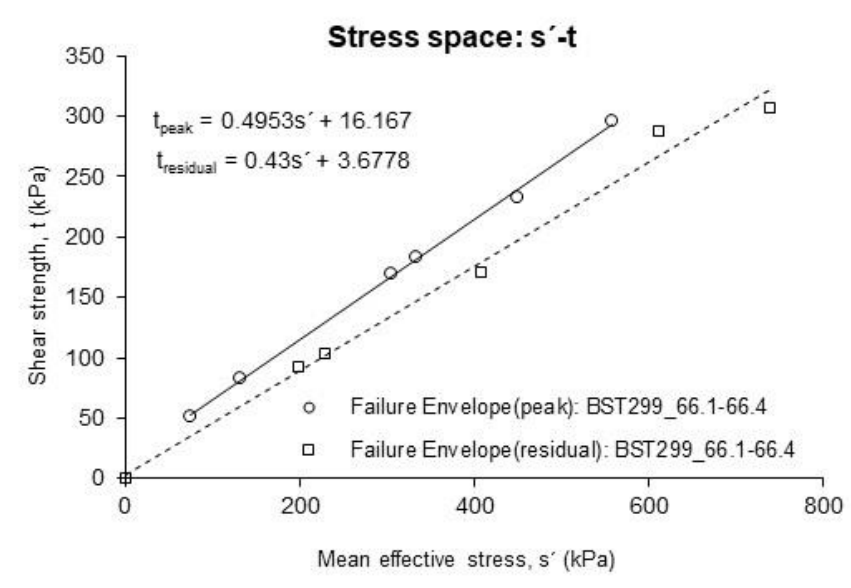

(a)

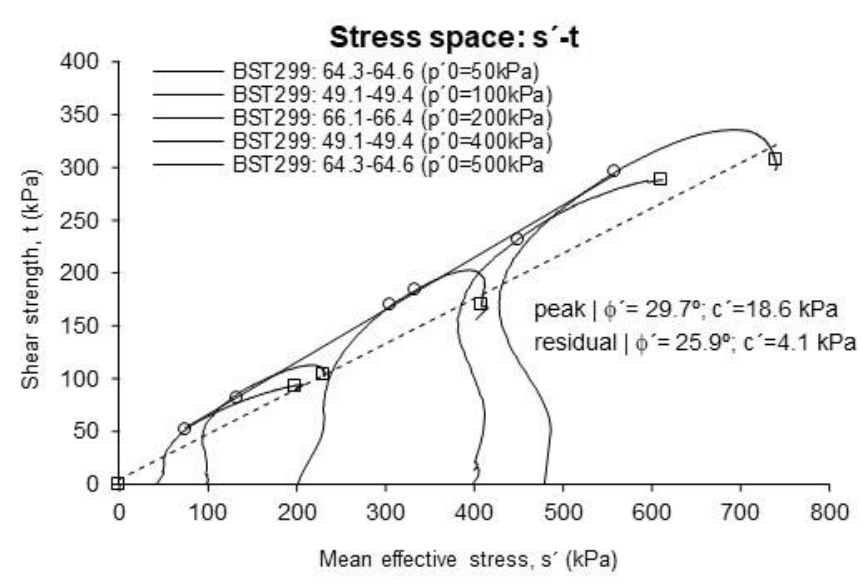

(b)

Figure 3. Result of unconsolidated undrained test. (a) Peak and residual failure envelop; (b) stress path.

In the Table 4, data, and strength parameters for S1_CZ sample tested are presented. Clay with low plasticity is deposited artificially and at the depth of the sample (49.1 to $66.4 \mathrm{~m}$ ), the increase in vertical stress will lead to over-consolidation. This is verified in the cohesion that the triaxial test reveal. The increase in mean effective stress during shear, reduces this strength effect.

Table 4. Failure envelope data for undrained triaxial test for S1_CZ sample in s'-t space.

\begin{tabular}{|c|c|c|c|c|c|c|}
\hline \multirow{2}{*}{\multicolumn{3}{|c|}{ Specimen Location }} & \multicolumn{4}{|c|}{ Failure Envelope Data $\left(s^{\prime}-t\right)$} \\
\hline & & & \multicolumn{2}{|c|}{ Peak } & \multicolumn{2}{|c|}{ Residual } \\
\hline Drilling hole: & BST 299 & & $\mathrm{t}(\mathrm{kPa})$ & $\mathrm{s}^{\prime}(\mathbf{k P a})$ & $\mathrm{t}(\mathrm{kPa})$ & $\mathrm{s}^{\prime}(\mathrm{kPa})$ \\
\hline Depth (m) & 49.1 to 66.4 & & 169.74 & 305.74 & 0 & 0 \\
\hline Date of Drilling: & $\begin{array}{c}14 \\
\text { September } \\
2016\end{array}$ & & 184 & 333.51 & 170.46 & 408.46 \\
\hline Date of Test: & $\begin{array}{r}16 \text { Decemb } \\
\text { Febru }\end{array}$ & $\begin{array}{l}016 \text { to } 22 \\
2017\end{array}$ & 51.3 & 74.3 & 93.02 & 197.92 \\
\hline \multirow[t]{3}{*}{ Specimen: } & S1_CZ & & 295.54 & 558.54 & 306.79 & 739.39 \\
\hline & & & 82.43 & 131.43 & 103.22 & 229.21 \\
\hline & & & 232.2 & 449.2 & 288.29 & 610.29 \\
\hline \multicolumn{3}{|c|}{ Strength parameters } & \multicolumn{4}{|c|}{ Failure envelope parameters } \\
\hline & peak & residual & & & & \\
\hline$\phi^{\prime}(0)=\arcsin \left(\tan \alpha^{\prime}\right)$ & 29.69 & 25.93 & $\mathrm{k}=$ & 16.167 & $\mathrm{k}=$ & 4 \\
\hline$c^{\prime}(k P a)=\frac{k}{\cos \left(\phi^{\prime}\right)}$ & 18.61 & 4.09 & $\left(\tan \alpha^{\prime}\right)=$ & 0.4953 & $\left(\tan \alpha^{\prime}\right)=$ & 0.4373 \\
\hline
\end{tabular}

For the critical level line, a single line is obtained of the type $q=m p^{\prime}\left(q_{c s}=0.552 p^{\prime}\right.$ $+28.269: \phi^{\prime}{ }_{\mathrm{cs}}=14^{\circ}$ ) in the q: $p^{\prime}$ (deviator stress: average effective stress) space that does not pass through the origin since it doesn't has reached the critical state to the axial strain 
of $20 \%$. The detailed pieces of information (results and questions) about behavior of specimens were described in the following study [9]. Yet stress path for $\mathrm{p}_{0}^{\prime}=350 \mathrm{kPa}$ reached the structural collapse for extensions close to the maximum stress strength. It is striking that the lines of failure points in the ultimate state (see Figure 4a) look analogous for the two samples and it is useful to compare these directly. The Isotropic State Line (ISL: $\left.v_{C S L}=-0.0008 \ln \left(p^{\prime}\right)+1.816: R^{2}=0.8785\right)$ in $v: \ln p^{\prime}$ (specific volume: mean effective stress) space (see Figure $4 \mathrm{~b}$ ) does not seem to be parallel to the critical state line determined (CSL: $\left.v_{C S L}=-0.0017 \ln \left(p^{\prime}\right)+2.007: R^{2}=0.8785\right)$ and these two lines tend to converge at higher stresses. With the rising of mean effective stress, the particles will start crashing which will imply that the dilatancy state parameter $(\psi)$, would probably decrease. We can define a compressible zone and softening by deformation below a zone of instability in relation to liquefaction.

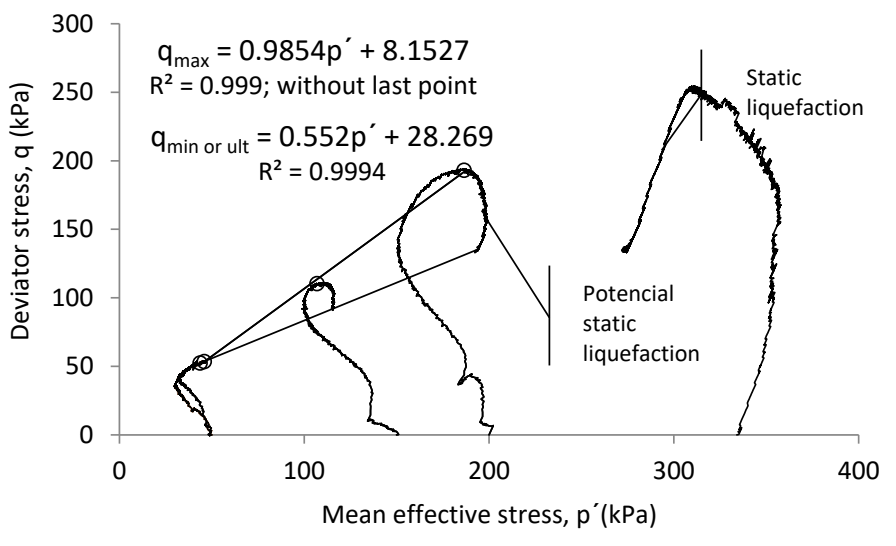

(a)

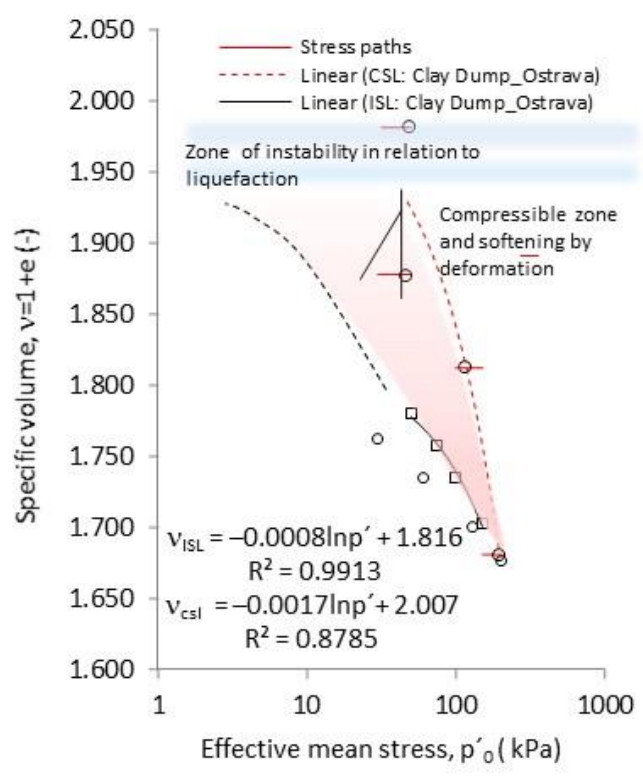

(b)

Figure 4. Failure points for undrained tests on Bohemia clay dump (S2 and S3) samples: (a) q:p' space—envelope for failure criteria $\left(\sigma_{1}-\sigma_{3}\right)_{\text {peak }}$ and $\left(\sigma_{1}-\sigma_{3}\right)_{\text {ult }} ;(\mathbf{b})$ volumetric space $\left(\lambda: \ln p^{\prime}\right)$.

The static liquefaction is true liquefaction, or a high softening deformation is associated with an extreme reduction of the peak strength imbrication for the critical state (Figure 4a). These peaks have been related to a hypothetical collapse, corresponding to the metastable rearrangement of particles. This is the normal shear strength silty/clay behavior of increasing liquefaction potential with an increase of confining pressure. The liquefaction potential index (LPI) is defined by Charles et al. (2004) as:

$$
\text { LPI }=\frac{q_{\max }-q_{\min }}{q_{\max }}
$$

where $\mathrm{q}_{\max }$ is maximum deviator stress (peak) and $\mathrm{q}_{\min }$ is minimum deviator stress (quasi steady state). The results of LPI for the CU tests are show in Table 5.

In stable material or to low confinement stress, both deviator stress [ $\mathrm{q}_{\max }=\left(\sigma_{1}-\right.$ $\left.\sigma_{3}\right)_{\text {peak }}$ and $\left.q_{\min }=\left(\sigma_{1}-\sigma_{3}\right)_{\text {residual }}\right]$ correspond to the same ultimate shear strength, so the LPI value is zero. The material is more instable when $\mathrm{q}_{\max }$ and $\mathrm{q}_{\min }$ become different and LPI value increases.

The effective internal frictional angle for peak strength $\left(\phi_{\text {peak }}^{\prime}\right)$ of the clean sample $\left(25^{\circ}\right)$ is basically equal to the soil contaminated with coal and is associated with the development of cohesion effect on the strength. 
Table 5. Liquefaction potential index (LPI) results of Bohemia clay dump (S2-S3).

\begin{tabular}{ccc}
\hline Specimen & $\mathbf{p}_{\mathbf{0}} \mathbf{0}_{\mathbf{( k P a}}$ & LPI \\
\hline S2I-CU50 & 50 & 0 \\
\hline S3I-CU50 & 50 & 0 \\
\hline S3R-CU150 & 150 & 0.16 \\
\hline S3-CU200 & 200 & 0.17 \\
\hline S3R2-CU350 & 350 & 0.47 \\
\hline
\end{tabular}

The cohesion effective or apparent of samples (S2 and S3) may be due to the connections established between fine particles. The cohesion effective explained by the transformation of the material and the connections established. Table 6 presents the values of mechanical parameters, effective internal frictional angle and cohesion $\left(\phi^{\prime}, c^{\prime}\right)$ in terms of $\left(\sigma_{1}-\sigma_{3}\right)_{\text {peak }}$ and $\left(\sigma_{1}-\sigma_{3}\right)_{\text {residual }}$ failure criteria, of the clean samples (S3) and contaminated sample (S2).

Table 6. Failure strength parameters for two criteria used of the Bohemia clay dump (S2-S3).

\begin{tabular}{cccc}
\hline \multicolumn{3}{c}{ Shear Parameters } \\
\hline Sample & \multicolumn{3}{c}{ S2:S3 (I and $\mathbf{R})$} \\
\hline Failure Criteria & $\boldsymbol{\phi}^{\prime}\left(^{\circ}\right)$ & $\mathbf{c}^{\prime} \mathbf{~ ( k P a )}$ & $\mathbf{R}^{\mathbf{2}}$ \\
\hline$\left(\sigma_{1}-\sigma_{3}\right)_{\text {peak }}$ & 25 & 4.2 & 0.983 \\
\hline$\left(\sigma_{1}-\sigma_{3}\right)_{\text {residual }}$ & 14 & 0.0 & 0.995 \\
\hline
\end{tabular}

\section{Conclusions}

This examination of data from physical, triaxial, and oedometer tests on the Bohemia clay dump (S2-S3) samples, revealed that the test results show:

- Particle size distribution and consistency test showed that the clay dump belongs to the CL group, S2 is a silty clay and S3 a sandy clay, which can be described as inorganic clay of low to medium plasticity with normal or low clayey activity $(0.56$ to 0.58 ). Thus, by indirect methods, there is a high probability of the existence of kaolinitic clay. Confirmed in electronic tests;

- The artificial lateral heart stress and the developed suction influenced an increase of virtual preconsolidation stress $\left(\sigma_{p *}^{\prime}\right)$ for the soils. The virtual preconsolidation stress is also dependent on depth position of sample or $\mathrm{K}_{0}$ in embankment;

- For the critical level line, a single line is obtained of the type $q={ }^{\prime} p^{\prime}\left(q_{c s}=0.552 p^{\prime}+\right.$ 28.269: $\phi^{\prime}{ }_{\mathrm{cs}}=14^{\circ}$ ) in the q:p' (deviator stress: average effective stress) space doesn't go through the origin because it has not reached the critical level to the axial strain of $20 \%$. Yet, stress path for $\mathrm{p}_{0}^{\prime}=350 \mathrm{kPa}$ reached the structural collapse for extensions close to the maximum stress strength;

- The Isotropic State Line (ISL: $\left.v_{\mathrm{CSL}}=-0.0008 \ln \left(\mathrm{p}^{\prime}\right)+1.816: \mathrm{R}^{2}=0.8785\right)$ in $v: \ln \mathrm{p}^{\prime}$ space looks as if non parallel to the critical state line obtained (CSL: $v_{\mathrm{CSL}}=-0.0017 \ln \left(\mathrm{p}^{\prime}\right)$ $\left.+2.007: R^{2}=0.8785\right)$. These lines tend to meet when applied mean effective stresses increase, meaning that the dilatancy parameter $(\psi)$ would probably decrease as the stress level increases, by the crushing and spatial reorganization of the particles. We can define a compressible zone and softening by deformation below a zone of instability in relation to liquefaction;

- The static liquefaction is a true liquefaction, or a high softening deformation is associated with an extreme reduction of the peak strength for medium to high confinement stress level. This can be seen with liquefaction potential index (LPI) for this soil and CU tests; 
- It was found that the maximum drop $\left(\mathrm{p}^{\prime}{ }_{0}=350 \mathrm{kPa}\right)$ in deviator stress after the peak, or the liquefaction potential $\left(\mathrm{q}_{\max }-\mathrm{q}_{\min }\right)$, during undrained shear, decreases as the confining pressure increases;

- Without understanding the properties of the dumps, it is not possible to safely predict their behavior at higher loads;

- They will also contribute to a safer design of structures on these materials, especially line and bridge objects.

Author Contributions: All authors have read and agreed to the published version of the manuscript.

Funding: Research and innovation for 2020 allocated to the VŠB-Technical University of Ostrava by the Ministry of Education, Youth and Sports of the Czech Republic.

Institutional Review Board Statement: Not applicable.

Informed Consent Statement: Not applicable.

Data Availability Statement: Not applicable.

Acknowledgments: The work is supported from fonds of the Conceptual development of science.

Conflicts of Interest: The authors declare no conflict of interest.

\section{References}

1. Burland, J.B. On the compressibility and shear strength of natural clays. Geotechnique 1990, 40, 329-378. [CrossRef]

2. Mantaras, F.M.; Schnaid, F. Cavity expansion in dilatant cohesive-frictional soils. Geotech. Eng. 2002, 143, 31-42.

3. Andrade Pais, L.J. Idealized zones on space of tensions of mechanical behaviour for the granitic residual soil from Covilhã. In Engineering Geology for Developing Countries; IAEG: Durban, South Africa, 2002; pp. 684-689.

4. Mashalah, K.; Amir, H.C.; Majid, T. Effects of crude oil contamination on geotechnical properties of clayey and sandy soils. Eng. Geol. 2007, 89, 220-229.

5. Charles, W.W.; Fung, W.T.; Cheuk, C.Y.; Zhang, L. Influence of stress ratio and stress path on behavior of loose decomposed granite. J. Geotech. Geoenviron. Eng. 2004, 130, 36-44.

6. Head, K.H. Manual of Soil Laboratory Testing; Engineering Laboratory Equipment Limited, Pentech Press: London, UK, 1980; Volume I-III.

7. BS 1377, British Standard. Methods of Test for Soils for CIvil Engineering Purpose; British Standards Institution (BSI): London, UK, 1990.

8. ASTM. Classification of soils for engineering purposes. In 1989 Standards Annual Book D2487-85; ASTM: Philadelphia, PA, USA, 2007; pp. 288-297.

9. Lahuta, H.; Pais, L.J.A.; Petrasova, T.; Phi, D.N. Laboratory test of dump material from coal mine. In Proceedings of the 16th International Multidisciplinary Scientific GeoConference SGEM, Bulgaria, Albena, 28 June-7 July 2016; Volume I, pp. 879-886. 